\title{
Comments on "Acoustic and Thermodynamic Properties of Binary Liquid Mixtures of Benzaldehyde in Hexane and Cyclohexane" by S. Azhagiri, S. Jayakumar, R. Padmanaban, S. Gunasekaran, and S. Srinivasan
}

\author{
Shantilal Oswal
}

Received: 25 August 2009 / Published online: 30 October 2009

(C) Springer Science+Business Media, LLC 2009

Keywords Acoustic properties · Liquid mixtures · Excess function · Molecular interactions · Benzaldehyde

In a recent paper, S. Azhagiri et al. [1] reported the acoustic and thermodynamic properties of binary liquid mixtures of benzaldehyde with hexane and with cyclohexane at $303.15 \mathrm{~K}$. These authors calculated so-called excess adiabatic compressibility $\left(\kappa_{S}^{\mathrm{E}}\right)$, intermolecular free length $\left(L_{f}^{\mathrm{E}}\right)$, acoustic impedance $\left(Z^{\mathrm{E}}\right)$, and ultrasonic velocity $\left(U^{\mathrm{E}}\right)$ from the equation $Y^{\mathrm{E}}=$ $Y-\left[(1-x) Y_{1}+x Y_{2}\right]$, where $Y$ denotes $\kappa_{S}, L_{f}, Z$ or $U$ of the mixtures; $x$ is the mole fraction of benzaldehyde (the solute) and subscripts 1 refers to benzaldehyde (solute) and 2 refers to hexane or cyclohexane (solvent). The results were reported in their Table 4 . The variation of $\kappa_{S}, L_{f}, Z$ or $U$ and $\kappa_{S}^{\mathrm{E}}, L_{f}^{\mathrm{E}}, Z^{\mathrm{E}}$ and $U^{\mathrm{E}}$ were discussed in terms of molecular interactions. I have several comments to make concerning this paper.

Their calculation [1] of $\kappa_{S}^{\mathrm{E}}, L_{f}^{\mathrm{E}}, Z^{\mathrm{E}}$, and $U^{\mathrm{E}}$ is wrong and erroneous, and thus the calculated values $\kappa_{S}^{\mathrm{E}}, L_{f}^{\mathrm{E}}, Z^{\mathrm{E}}$, and $U^{\mathrm{E}}$ are not the claimed excess properties. The reported experimental density and ultrasonic velocity data for the pure components are also quite different from reliable literature values, and their interpretation of the reported results is unrealistic.

First, values of $\kappa_{S}^{\mathrm{E}}, L_{f}^{\mathrm{E}}, Z^{\mathrm{E}}$, and $U^{\mathrm{E}}$, their so-called excess properties (in fact they are actually deviations from mole fraction averages: $\Delta \kappa_{S}, \Delta L_{f}, \Delta Z$ or $\Delta U$ ) when $x=0$ or 1 unexpectedly have significant finite values, whereas, in fact they should be zero. I recalculated and analyzed the data looking for the error. It became clear that the authors have made a gross error in using the equation $Y^{\mathrm{E}}=Y-\left[(1-x) Y_{1}+x Y_{2}\right.$, their Eq. 6. In fact, this equation should actually be

$$
\Delta Y=Y-\left[x Y_{1}+(1-x) Y_{2}\right]
$$

S. Oswal $(\varangle)$

Biochemistry Division, R. \& D. Span Diagnostic Limited, 173-B, New Industrial Estate, Udhna,

Surat 394210, India

e-mail: oswals1@yahoo.co.uk 
Table 1 Values of deviations in the ultrasonic velocity, adiabatic compressibility, acoustic impedance, and intermolecular free length of binary systems at $(303.15 \pm 0.05) \mathrm{K}$

\begin{tabular}{lllll}
\hline$x_{1}$ & $\Delta U$ & $\left(\Delta \kappa_{S}\right) \times 10^{9}$ & $(\Delta Z) \times 10^{-6}$ & $\left(\Delta L_{f}\right) \times 10^{10}$ \\
& $\mathrm{~m} \cdot \mathrm{s}^{-1}$ & $\mathrm{~m}^{2} \cdot \mathrm{N}^{-1}$ & $\mathrm{~kg} \cdot \mathrm{m}^{-2} \cdot \mathrm{s}^{-1}$ & $\mathrm{~m}$ \\
\hline
\end{tabular}

Benzaldehyde (1) + hexane (2)

$\begin{array}{rrrrr}0.0 & 0.0 & 0.0000 & 0.0000 & 0.0000 \\ 0.1 & -29.9 & 0.0351 & -0.0587 & 0.0164 \\ 0.2 & -45.8 & 0.0188 & -0.0906 & 0.0167 \\ 0.3 & -39.7 & -0.0341 & -0.0977 & 0.0038 \\ 0.4 & -40.6 & -0.0721 & -0.0893 & -0.0070 \\ 0.5 & -33.5 & -0.0887 & -0.0862 & -0.0127 \\ 0.6 & -34.4 & -0.0913 & -0.0714 & -0.0153 \\ 0.7 & 7.7 & -0.1226 & -0.0054 & -0.0323 \\ 0.8 & -10.2 & -0.0689 & -0.0362 & -0.0150 \\ 0.9 & -9.1 & -0.0328 & -0.0302 & -0.0061 \\ 1.0 & 0.0 & 0.0000 & 0.0000 & 0.0000\end{array}$

Benzaldehyde (1) + cyclohexane (2)

\begin{tabular}{rrrrr}
0.0 & 0.0 & 0.0000 & 0.0000 & 0.0000 \\
0.1 & -16.2 & 0.0116 & -0.0313 & 0.0065 \\
0.2 & -8.4 & -0.0184 & -0.0264 & -0.0026 \\
0.3 & 27.4 & -0.0725 & 0.0086 & -0.0225 \\
0.4 & 19.2 & -0.0638 & -0.0052 & -0.0187 \\
0.5 & 27.0 & -0.0760 & 0.0154 & -0.0242 \\
0.6 & 10.8 & -0.0535 & -0.0066 & -0.0155 \\
0.7 & 0.6 & -0.0403 & -0.0085 & -0.0111 \\
0.8 & 25.4 & -0.0487 & 0.0243 & -0.0172 \\
0.9 & 10.2 & -0.0262 & 0.0187 & -0.0094 \\
1.0 & 0.0 & 0.0000 & 0.0000 & 0.0000 \\
\hline
\end{tabular}

In place of $x$, they have wrongly used $(1-x)$ and vice versa. To emphasize the point, recalculated results using Eq. 1 are reported in Table 1. Unlike the authors' reported values, there is a regular variation in $\Delta U, \Delta \kappa_{S}, \Delta Z$, or $\Delta L_{f}$ as the mole fraction composition $x$ is varied. Further, it seems that the values of ultrasonic velocity at $x=0.7$ are in error for benzaldehyde + hexane. The values of $\kappa_{S}^{\mathrm{E}}, L_{f}^{\mathrm{E}}, Z^{\mathrm{E}}$, and $U^{E}$ obtained by Azhagiri et al. [1] are unreliable, and are therefore inappropriate for interpretation. By implication, the discussion of the authors' values for $\kappa_{S}^{\mathrm{E}}, L_{f}^{\mathrm{E}}, Z^{\mathrm{E}}$, and $U^{\mathrm{E}}$ is also inappropriate. If one wants to calculate true excess functions $Y^{\mathrm{E}}$, then the following expressions should be used

$$
Y^{\mathrm{E}}=Y-Y^{\mathrm{id}}
$$

where $Y$ is either $\kappa_{S}, L_{f}$ or $U$.

Values of $\kappa_{S}^{\text {id }}, U^{\text {id }}$ and $L_{f}^{\text {id }}$ for an ideal mixture were calculated from the relations recommended by Bertrand and Smith [2], Benson and Kiyohara [3], and Douheret et al. $[4,5]:$

$$
\kappa_{S}^{\mathrm{id}}=\sum \phi_{i}\left\{\kappa_{\mathrm{S}, \mathrm{i}}^{\mathrm{o}}+T V_{i}^{\mathrm{o}}\left(\alpha_{i}^{\mathrm{o}}\right)^{2} / C_{p, i}^{\mathrm{o}}\right\}-T\left(\Sigma x_{\mathrm{i}} V_{i}^{\mathrm{o}}\right)\left(\Sigma \phi_{i} \alpha_{i}^{\mathrm{o}}\right)^{2} / \Sigma x_{i} C_{p, i}^{\mathrm{o}}
$$


Table 2 Values of the excess ultrasonic velocity, adiabatic compressibility, and intermolecular free length of binary system at $(303.15 \pm 0.05) \mathrm{K}$

\begin{tabular}{llll}
\hline$x_{1}$ & $U^{\mathrm{E}}$ & $\left(\kappa_{S}^{\mathrm{E}}\right) \times 10^{9}$ & $\left(L_{f}^{\mathrm{E}}\right) \times 10^{10}$ \\
& $\mathrm{~m} \cdot \mathrm{s}^{-1}$ & $\mathrm{~m}^{2} \cdot \mathrm{N}^{-1}$ & $\mathrm{~m}$ \\
\hline
\end{tabular}

Benzaldehyde (1) + hexane (2)

$\begin{array}{lrrr}0.1 & 6 & 0.013 & 0.0101 \\ 0.2 & 23 & -0.021 & 0.0059 \\ 0.3 & 57 & -0.088 & -0.0100 \\ 0.4 & 80 & -0.135 & -0.0227 \\ 0.5 & 105 & -0.156 & -0.0293 \\ 0.6 & 114 & -0.157 & -0.0314 \\ 0.7 & 154 & -0.182 & -0.0461 \\ 0.8 & 118 & -0.116 & -0.0261 \\ 0.9 & 76 & -0.060 & -0.0126\end{array}$

Benzaldehyde (1) + cyclohexane (2)

\begin{tabular}{lrrr}
0.1 & 3 & 0.005 & 0.0055 \\
0.2 & 27 & -0.030 & -0.0038 \\
0.3 & 76 & -0.087 & -0.0234 \\
0.4 & 77 & -0.081 & -0.0201 \\
0.5 & 91 & -0.093 & -0.0255 \\
0.6 & 76 & -0.070 & -0.0171 \\
0.7 & 62 & -0.055 & -0.0126 \\
0.8 & 75 & -0.060 & -0.0180 \\
0.9 & 41 & -0.032 & -0.0099 \\
\hline
\end{tabular}

$$
\begin{aligned}
& \left.U^{\mathrm{id}}=\left(\Sigma_{i} \phi_{i} \rho_{i}^{\mathrm{o}}\right) \kappa_{S}^{\mathrm{id}}\right)^{-1 / 2} \\
& L_{f}^{\mathrm{id}}=\sum_{i} \Sigma_{i} \phi_{i} L_{f, i}
\end{aligned}
$$

in which $V_{i}^{\mathrm{o}}, \rho_{i}^{\mathrm{o}}, \alpha_{i}^{\mathrm{o}}, C_{p, i}^{\mathrm{o}}$, and $L_{f, i}$ are, respectively, the molar volume, density, isobaric thermal expansion coefficient, molar isobaric heat capacity, and intermolecular free length of pure component $i$, and $\phi_{i}=x_{i} V_{i} / \Sigma x_{j} V_{j}$ is the volume fraction of $i$ in the mixtures calculated in terms of the unmixed pure components. The excess properties $\kappa_{S}^{\mathrm{E}}, U^{\mathrm{E}}$ and $L_{f}^{\mathrm{E}}$ calculated from Eqs. 2 to 5 are reported in Table 2, for comparison with $\Delta \kappa_{S}, \Delta U$ and $\Delta L_{f}$ and to show the difference between the two sets of quantities. It is obvious that both sets of parameters have significant differences; therefore, the estimation of intermolecular interactions from deviations calculated by Eq. 1 seems to be unjustified and the conclusions are rather misleading.

Second, the interpretation provided throughout their paper [1] seems to be totally out of place, unrealistic and misleading. The interpretation by the authors that "the decrease of $\kappa_{S}$ and $L_{f}$, and also the increase in $R_{a}$ and $Z$, with increasing mole fraction of benzaldehyde in both liquid systems indicates the presence of molecular interactions between unlike molecules" does not seem right. It is well known that when two liquid components having largely different properties are mixed, significant variation in the properties is bound to occur, either a decrease or an increase, depending upon the properties of the individ- 
Table 3 Comparison of the reported experimental values of the ultrasonic velocity and density of pure liquids with literature values at $303.15 \mathrm{~K}$

\begin{tabular}{llllll}
\hline \multirow{2}{*}{ Liquid } & \multicolumn{2}{l}{ Ultrasonic velocity $(U), \mathrm{m} \cdot \mathrm{s}^{-1}$} & & \multicolumn{2}{l}{ Density $(\rho), \mathrm{kg} \cdot \mathrm{m}^{-3}$} \\
\cline { 2 - 3 } & Reference [1] & Literature & & Reference [1] & Literature \\
\hline Benzaldehyde & 1464 & $1447[6]$ & & 1049 & $1035.6[7]$ \\
Hexane & 1075 & $1053.7[8]$ & & 675 & $650.56[10]$ \\
& & $1054[9]$ & & & $650.18[7]$ \\
Cyclohexane & 1202 & $1229.1[11]$ & & 790 & $769.04[10]$ \\
& & $1230[12]$ & & & $768.45[7]$ \\
\hline
\end{tabular}

ual components. In this particular case, when benzaldehyde having a low compressibility $\left(0.445 \times 10^{-9} \mathrm{~m}^{2} \cdot \mathrm{N}^{-1}\right.$ or $\left.445 \mathrm{TPa}^{-1}\right)$ is added to a component having a higher compressibility, cyclohexane $\left(0.876 \times 10^{-9} \mathrm{~m}^{2} \cdot \mathrm{N}^{-1}\right.$ or $\left.876 \mathrm{TPa}^{-1}\right)$ or hexane $\left(1.283 \times 10^{-9} \mathrm{~m}^{2} \cdot \mathrm{N}^{-1}\right.$ or $1283 \mathrm{TPa}^{-1}$ ), then the values of $\kappa_{S}$ of the mixture should decrease. To analyze the molecular interactions, it is important to know the size of these decreases. In other words, how large is the deviation from its reference state (ideal values from Eq. 2, combined with Eqs. 3-5) or from mole fraction or volume fraction averages. Because the calculation of their so-called excess properties through Eq. 6 of the original paper [1] (in fact these are normally called deviations from mole fraction additivity or averages) was incorrect, the discussion and interpretation by the authors is incorrect.

Also, it is worth pointing out that authors made statements about weak and strong dipoledipole interaction and $\mathrm{H}$-bonding [1]. The authors should remember that neither cyclohexane nor hexane has a dipole moment. Similarly, there is no hydrogen bond in benzaldehyde molecules, and neither cyclohexane nor hexane can form H-bonds with benzaldehyde. In fact, it is dispersion interactions and/or breaking of dipolar order in benzaldehyde that is responsible for most of the interactions in these types of mixtures. In that case, the values of $\kappa_{S}^{\mathrm{E}}$ should have been positive.

Third, the reported ultrasonic velocity and density data of the pure components (see Table 3) are quite different from reliable literature data. The values of $U$ differ by 17 to $28 \mathrm{~m} \cdot \mathrm{s}^{-1}$ and densities by 13 to $24 \mathrm{~kg} \cdot \mathrm{m}^{-3}$, which will add substantial uncertainty to the final calculated results.

Fourth, the authors have stated [1] that the use of their Eqs. 7 to 9 provide theoretical estimates of the ultrasonic velocity of mixtures. In fact, all three relations are empirical rather than theoretical. Therefore, it will be more correct to write that the ultrasonic velocity was estimated from empirical relations.

Finally, it is proper to emphasize here that, once the correct expression for calculating the ideal isentropic compressibility is known, one should use only that expression to derive the excess isentropic compressibility and hence the correct excess ultrasonic velocity, rather than using the approximate mole fraction or volume fraction averages. Recently, many authors [13-18] have continued to predict molecular interactions from the deviations calculated using mole fraction or volume fraction averages rather than using the correct equations described herein.

\section{References}

1. Azhagiri, S., Jayakumar, S., Padmanaban, R., Gunasekaran, S., Srinivasan, S.: Acoustic and thermodynamic properties of binary liquid mixtures of benzaldehyde in hexane and cyclohexane. J. Solution Chem. 38, 441-448 (2009) 
2. Bertrand, G.L., Smith, L.E.: Isentropic compressibility of ideal solutions. J. Phys. Chem. 74, 4171-4172 (1974)

3. Benson, G.C., Kiyohara, O.: Evaluation of excess isentropic compressibilities and isochoric heat capacities. J. Chem. Thermodyn. 11, 1061-1064 (1979)

4. Douheret, G., Moreau, C., Viallard, A.: Excess thermodynamic quantities in binary systems of non electrolytes. I. Different ways of calculating excess compressibilities. Fluid Phase Equilib. 22, 277-287 (1985)

5. Douheret, G., Davis, M.I., Reis, J.C.R., Blandamer, M.J.: Isentropic compressibilities-Experimental origin and the quest for their rigorous estimation in thermodynamically ideal liquid mixtures. Chem. Phys. Phys. Chem. 2, 148-161 (2001)

6. Pandey, J.D., Kumar, A.: Ultrasonic velocity in pure liquids. J. Pure Appl. Ultrasonics 16, 65-68 (1994)

7. Riddick, J.A., Bunger, W.B., Sakano, T.K.: Organic Solvents: Physical Properties and Methods of Purification. Wiley, New York (1986)

8. Schaaffs, W.: Molecularakustic. Springer, Berlin (1963)

9. Oswal, S.L., Phalak, R.P.: Speed of sound and isentropic compressibilities of nonelectrolyte liquid mixtures. I. Binary mixtures containing $p$-dioxane. J. Solution Chem. 22, 43-58 (1993)

10. Stokes, R.H.: Dielectric constants and molar polarizations of cycloalkanes, benzene, $n$-hexane, and carbon tetrachloride in the range 278 to 343 K. J. Chem. Thermodyn. 5, 379-385 (1973)

11. Tamura, K., Murakami, S., Doi, S.: Speeds of sound, densities, and isentropic compressibilities of $\left\{x \mathrm{c}-\mathrm{C}_{6} \mathrm{H}_{12}+(1-x) \mathrm{C}_{6} \mathrm{H}_{5} \mathrm{CH}_{3}\right\},\left\{x \mathrm{c}-\mathrm{C}_{6} \mathrm{H}_{11} \mathrm{CH}_{3}+(1-x) \mathrm{C}_{6} \mathrm{H}_{6}\right\}$, and $\left\{x \mathrm{c}-\mathrm{C}_{6} \mathrm{H}_{11} \mathrm{CH}_{3}+(1-\right.$ $\left.x) \mathrm{C}_{6} \mathrm{H}_{5} \mathrm{CH}_{3}\right\}$, from 293.15 to 303.15 K. J. Chem. Thermodyn. 17, 325-333 (1985)

12. Oswal, S.L., Prajapati, K.D.: Speeds of sound, isentropic compressibilities, and excess molar volumes of an alkanol + cycloalkane at 303.15 K. 1. Results for alkan-1-ols + cyclohexane. J. Chem. Eng. Data 43, 367-372 (1998)

13. Roy, M.N., Sinha, A.: Viscous synergy and antagonism and isentropic compressibility of ternary mixtures containing 1,3-dioxolane, water and monoalkanols at 303.15 K. Fluid Phase Equilib. 243, 133-141 (2006)

14. Hasan, M., Shirude, D.F., Hiraya, A.P., Kadam, U.P., Sawant, A.B.: Densities, viscosities and ultrasonic velocity studies of binary mixtures of toluene with heptan-1-ol, octan-1-ol and decan-1-ol at 298.15 and 308.15 K. J. Mol. Liq. 135, 32-37 (2006)

15. Roy, M.N., Sinha, B.: Viscous synergy and isentropic compressibility of some monoalkanols and cyclic ethers in water at 298.15 K. J. Mol. Liq. 133, 88-99 (2007)

16. Gnana Kumari, P., Venkatesu, P., Prabhakara Rao, M.V., Lee, M.-J., Lin, H.-M.: Excess molar volumes and ultrasonic studies of N-methyl-2-pyrrolidone with ketones at $T=303.15 \mathrm{~K}$. J. Chem. Thermodyn. 41, 586-590 (2009)

17. Nain, A.K.: Ultrasonic and viscometric studies of molecular interactions in binary mixtures of formamide with ethanol, 1-propanol, 1,2-ethanediol and 1,2-propanediol at different temperatures. J. Mol. Liq. 140, 108-116 (2008)

18. Bhatia, S.C., Bhatia, R., Dubey, G.P.: Thermophysical and sonochemical behaviour of binary mixtures of decan-1-ol with halohydrocarbons at $(T=293.15$ and 313.15) K. J. Chem. Thermodyn. 42, 114-127 (2010). doi:10.1016/j.jct.2009.05.001 